Research Article

\title{
Novel, Rapid, Isocratic RP-HPLC Method for Simultaneous Estimation of Piperine and Embelin in Herbal Formulation
}

\author{
Vandana Jain*, Revati Sonone, Leena Tandel \\ Department of Quality Assurance, Oriental College of Pharmacy, Sanpada - Navi Mumbai, Maharashtra, India. \\ *Corresponding author's E-mail: vandana.jain@ocp.edu.in
}

Received: 10-06-2020; Revised: 04-09-2021; Accepted: 13-09-2021; Published on: 15-10-2021.

\section{ABSTRACT}

The objective of this paper was to develop and validate a novel, simple, rapid, precise and accurate, reverse-phase high-performance liquid chromatographic (RP-HPLC) method for simultaneous quantitative estimation of piperine and embelin in the herbal formulation as per the International Conference on Harmonization guidelines (ICH). Chromatographic separation was achieved using a Cosmosil C-18 $(250 * 4.6 \mathrm{~mm}) \mathrm{SH} 5.0 \mu \mathrm{m}$ column with a mobile phase consisting of methanol and $0.02 \mathrm{M}$ phosphate buffer in ratio $98: 2 \mathrm{v} / \mathrm{v}$, (pH adjusted to 2.3 with ortho-phosphoric acid) at a flow rate of $1 \mathrm{~mL} / \mathrm{min}$ and column temperature maintained at $28^{\circ} \mathrm{C}$ and ultraviolet (UV) detection at $288 \mathrm{~nm}$. The retention time of piperine and embelin was found to be 4.15 and 5.69 min respectively. The linearity of piperine and embelin was tested in the range of 5-40 $\mu \mathrm{g} / \mathrm{mL}$. The correlation coefficient for piperine and embelin was found to be 0.997 and 0.995 , respectively. The recovery values $(98-102 \%)$ indicate a satisfactory accuracy. The method was found to be precise as the percentage relative standard deviation was found to be $<2 \%$. The proposed novel isocratic RP-HPLC method is rapid (short run time below $10 \mathrm{~min}$ ), precise, accurate and sensitive. The method was successfully applied for the simultaneous analysis of piperine and embelin in herbal formulation.

Keywords: Piperine, embelin, herbal formulation, Reverse-phase high-performance liquid chromatographic, Validation.

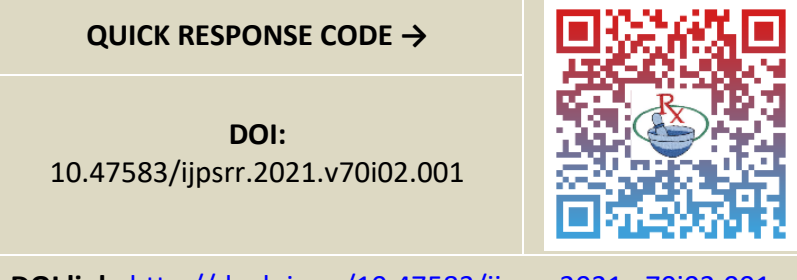

DOI link: $\underline{\text { http://dx.doi.org/10.47583/ijpsrr.2021.v70i02.001 }}$

\section{INTRODUCTION}

$\mathrm{H}$ erbal medicines widely used in health-care in both developed and developing countries. ${ }^{1-2}$ Herbals are traditionally considered harmless and effective. To ensure the quantity, quality, safety, and therapeutic effect of ingredients in each dose, standardization of herbal drug is essential. Standardization minimizes batch to batch variation of the polyherbal formulation. ${ }^{3}$

The present study focuses on the standardization of an herbal formulation using high- performance liquid chromatography. Fattolin is a well-known marketed herbal formulation that is indicated mainly against obesity, high chlolesterol, supportive in cardiac diseases, arthritis.

The selected ayurvedic formulation consists of powder of Shunthi (Zingiber officinale), Marich (Piper nigrum), Pippali (Piper longum), Chitrak (Plumbago zeylanica), Vidanga (Embelia ribes), Shuddha Gandhak 20mg. each, Kanchnar (Bauhinia variegata), Gokshur (Tribulus terrestris) $40 \mathrm{mg}$. each, Triphala, Shuddha Guggul (Balsamodendron mukul) $100 \mathrm{mg}$ each, two chemical markers, one from each medicinal herb, were selected for the present work, namely, embelin from Embelia ribes and piperine from Piper nigrum.

Embelin exhibits diverse biological activities which mainly include anxiolytic, anticonvulsant, antidepressant, antidiabetic, wound healing, anthelmintic, antimicrobial, antitumor, chemopreventive, antioxidant, antifertility as reported in various literature. ${ }^{4}$ Piperine is an alkaloid from Piper nigrum, commonly used as a spice due to the pungent and biting taste of piperine. ${ }^{5}$ Piperine possesses antidepressant, antioxidant, hepatoprotective, antiplatelet, antithyroid, antitumor, antihypertensive, antiinflammatory, bioenhancer effect. ${ }^{6}$

The literature survey reveals that various analytical methods for the estimation of embelin and piperine were reported alone and in combination with other drugs. ${ }^{7-10}$ However, no isocratic high-performance liquid chromatography (HPLC) method has been reported for the simultaneous estimation of embelin and piperine. Therefore, an attempt has been taken to develop a novel isocratic reverse-phase HPLC method for the simultaneous estimation of embelin and piperine in the herbal formulation and validate the developed method in accordance with the International Council for Harmonization (ICH). ${ }^{11}$

\section{MATERIALS AND METHODS}

\section{Instrument}

HPLC chromatographic separation was performed on Shimadzu (LC 2030) model with Lab Solution software. 
Ultraviolet (UV)-visible spectrometer was used for obtaining the maximum wavelength of compounds.

\section{Standards and reagents}

HPLC grade embelin and piperine (purity 99\%) were purchased from Sigma-Aldrich, Mumbai, India. Herbal formulation of Fattolin tablet (Sharangdhar Pharmaceuticals Pvt. Ltd, Pune, India) used for analysis was purchased from the local market. HPLC grade solvents were purchased from Thermo Fisher Scientific India Pvt. Ltd.

\section{Chromatographic conditions}

RP-HPLC Shimadzu LC Prominence-i 2030 model with Lab Solution software was employed in this method. The separation of embelin and piperine was carried on Shimadzu Cosmosil C-18 (250*4.6mm) SH $5.0 \mu \mathrm{m}$ column. The mobile phase used was methanol and $0.02 \mathrm{M}$ phosphate buffer in the ratio $(98: 2 \mathrm{v} / \mathrm{v})$ at a flow rate of 1 $\mathrm{mL} / \mathrm{min}$, injection volume was $20 \mu \mathrm{L}$, column temperature was $28^{\circ} \mathrm{C}$, and standard solution of piperine and embelin were prepared and scanned separately in the range of 200$400 \mathrm{~nm}$. The $288 \mathrm{~nm}$ wavelength was selected as detection wavelength for the detection of piperine and embelin.

\section{Preparation of (0.02 M) phosphate buffer (pH 2.3)}

About $2.72 \mathrm{~g}$ of potassium dihydrogen phosphate buffer was accurately weighed and then dissolved in $950 \mathrm{~mL}$ of water. The $\mathrm{pH}$ was adjusted to 2.3 with ortho-phosphoric acid, and the volume was made up to $1000 \mathrm{~mL}$ in a volumetric flask. The solution was then filtered

\section{Preparation of standard stock solution}

The standard stock solutions containing $100 \mathrm{mg}$ each of piperine and embelin were prepared separately in $100 \mathrm{~mL}$ volumetric flask and then the volume was made up to methanol to obtain a stock solution of $1000 \mu \mathrm{g} / \mathrm{mL}$. The stock solution was used for further analysis after suitable dilutions.

\section{Preparation of sample solution}

Ten tablets were triturated and $1 \mathrm{~g}$ of powder was accurately weighed and then taken for extraction. The powder was extracted with methanol for 30 min using the reflux assembly. The extract was made up to $100 \mathrm{~mL}$ with methanol. The solution was then filtered through Whatman filter paper to obtain a clear solution. The solution was injected after suitable dilutions.

\section{RESULTS AND DISCUSSION}

\section{Method development}

Different trials were carried out using methanol: phosphate buffer with varying concentrations. When a mixture of methanol: phosphate buffer $(80: 20 \mathrm{v} / \mathrm{v})$ was used, the peak of piperine was obtained but embelin was not eluted. When a mobile phase consisting of methanol: phosphate buffer $(90: 10 \mathrm{v} / \mathrm{v})$ was used, the peak of piperine was obtained but there was tailing in embelin peak. A satisfactory result was achieved at methanol and $0.02 \mathrm{M}$ phosphate buffer $(\mathrm{pH} 2.3$ adjusted with orthophosphoric acid) in a ratio of $98: 2 \mathrm{v} / \mathrm{v}$ at flow rate $1 \mathrm{ml} / \mathrm{min}$ followed by detection at $288 \mathrm{~nm}$ respectively. The injection volume was kept $20 \mu \mathrm{L}$. The total run time were set at 7 minutes respectively. The column temperature was set at $28^{\circ} \mathrm{C}$. The retention time of piperine and embelin obtained was $4.15 \mathrm{~min}$ and $5.69 \mathrm{~min}$ respectively. Chromatograms of mixed standard and sample solution are shown in Fig. 12.

$\mathrm{mV}$

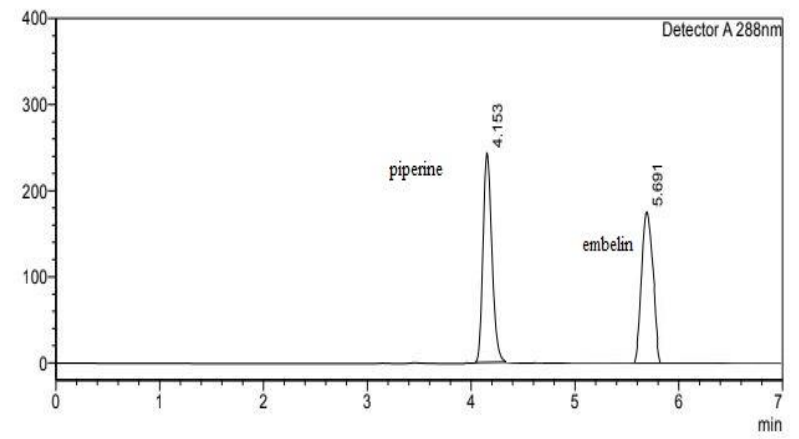

Figure 1: A typical RP-HPLC chromatogram of standard mixture of piperine and embelin obtained using optimized conditions

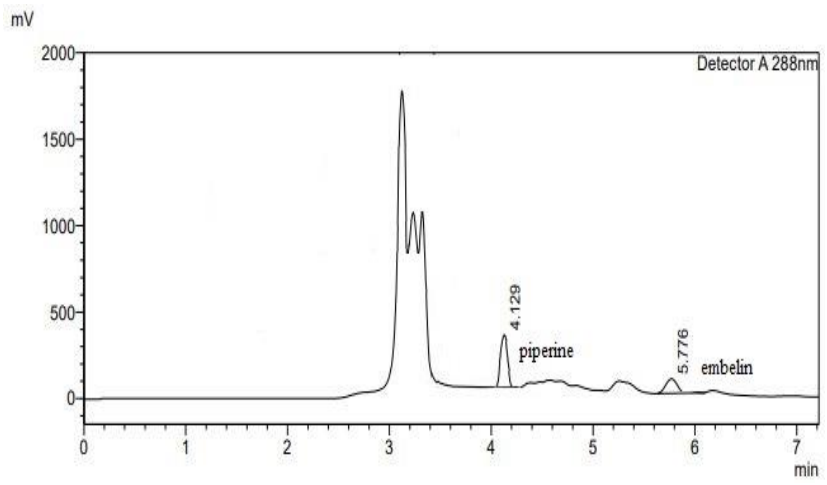

Figure 2: A typical RP-HPLC chromatogram of sample solution using optimized chromatographic conditions

\section{Method validation}

The developed method was validated for parameters such as specificity, precision, linearity, accuracy, robustness, limit of detection (LOD) and limit of quantification (LOQ) as per ICH guidelines. ${ }^{11}$

\section{Specificity}

Chromatograms of mixed standard and sample solution reveals that the peaks obtained are just because of the marker compound and blank has no peak at the retention time of piperine and embelin. Hence, the method is said to be specific.

\section{Precision}

Precision includes system precision and method precision. The system precision was carried out by injecting six injections of mixed standard of piperine and embelin. Method precision was performed by injecting the sample 
solution of the same concentration six times. The percentage relative standard deviation (\% RSD) was found to be less than 2 . Therefore, the method is found to be precise. The system and method precision data are tabulated in table 1 and 2 .

Table 1: Result of system precision

\begin{tabular}{|c|c|c|}
\hline S. No & $\begin{array}{c}\text { Peak area of } \\
\text { piperine }(\mathbf{1 0} \boldsymbol{\mu g} / \mathbf{m L})\end{array}$ & $\begin{array}{c}\text { Peak area of } \\
\text { embelin }(\mathbf{1 0} \boldsymbol{\mu g} / \mathbf{m L})\end{array}$ \\
\hline 1. & 1441961 & 1754696 \\
\hline 2. & 1428698 & 1746752 \\
\hline 3. & 1467324 & 1763746 \\
\hline 4. & 1446276 & 1764732 \\
\hline 5. & 1434760 & 1753821 \\
\hline 6. & 1485436 & 1746849 \\
\hline Mean \pm & $1450743 \pm 21527$ & $1755099 \pm 7837$ \\
\hline SD & & 0.45 \\
\hline
\end{tabular}

\# SD: standard deviation, \# \%RSD: percent relative standard deviation

Table 2: Result of method precision

\begin{tabular}{|c|c|c|}
\hline S. No & $\begin{array}{c}\text { Peak area of } \\
\text { piperine }\end{array}$ & Peak area of embelin \\
\hline 1. & 1269051 & 884436 \\
\hline 2. & 1246278 & 882614 \\
\hline 3. & 1272763 & 874269 \\
\hline 4. & 1223792 & 886107 \\
\hline 5. & 1250287 & 879462 \\
\hline 6. & 1236273 & 887598 \\
\hline Mean \pm & $1249741 \pm 18814$ & $882414 \pm 4893$ \\
\hline SD & & 0.55 \\
\hline
\end{tabular}

\# SD: standard deviation, \# \%RSD: percent relative standard deviation

\section{Linearity}

The linearity between peak area and concentration was analyzed using calibration curves obtained with standard solutions of piperine and embelin with different concentrations of each standard. The proposed method was found to be linear over a wide range of concentrations $5-40 \mu \mathrm{g} / \mathrm{ml}$ for piperine and embelin with a regression coefficient of 0.997 and 0.995 , respectively. Hence, the method was found to be linear. The plots obtained from linear regression are shown in fig. 3 and fig. 4.

\section{Quantification of marker in the formulation}

Quantification of the markers was done by performing HPLC analysis of sample solutions. The amount of piperine and embelin present in the formulation was calculated using linear regression analysis. The \% content of piperine and embelin was found to be 0.05 and $0.02 \% \mathrm{w} / \mathrm{w}$ respectively.

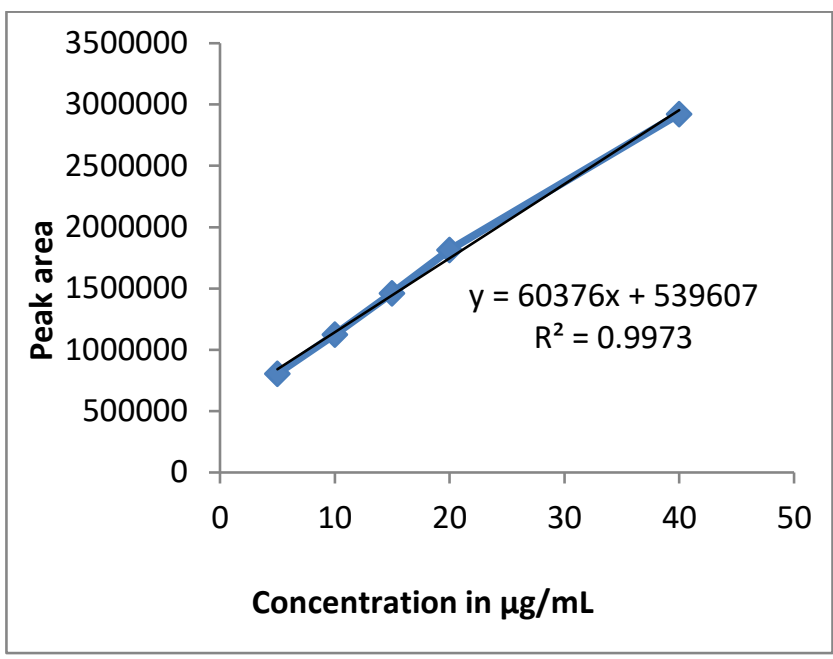

Figure 3: Calibration curve of piperine

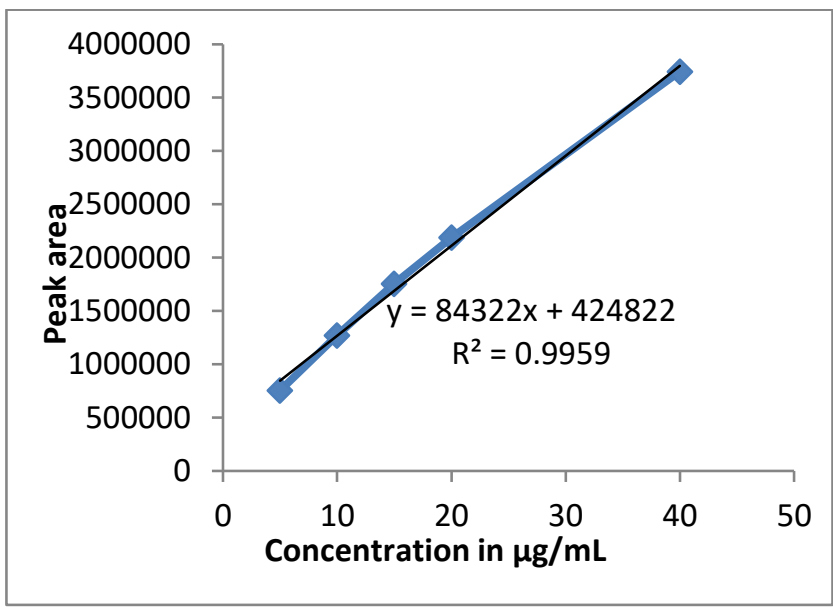

Figure 4: Calibration curve of embelin

\section{Accuracy}

Recovery of piperine and embelin from formulation was checked by spiking a known quantity of standards at three concentration levels (i.e. $80 \%, 100 \%$ and $120 \%$ of the quantified amount) to the test samples in triplicate using HPLC. This way, accuracy was performed and calculated. The $\%$ recovery was observed to be within the acceptance criterion of 98-102\% and the results are tabulated in table 3 for piperine and embelin respectively.

\section{Robustness}

The developed method was evaluated for robustness by small deliberate changes in optimized method parameters which were carried out with sample solution by making deliberate changes in flow rate $( \pm 0.1 \mathrm{ml} / \mathrm{min})$, column temperature $\left( \pm 1^{\circ} \mathrm{C}\right)$, and wavelength $( \pm 1 \mathrm{~nm})$. The $\%$ RSD of peak area response of the test solution was found to be less than 2.0, hence the robustness parameters were found to be acceptable. The robustness results are tabulated in table 4. 
Table 3: Percentage recovery results for piperine and embelin

\begin{tabular}{|c|c|c|c|c|c|c|}
\hline Compound & Level \% & $\begin{array}{c}\text { Sample } \\
(\mu \mathrm{g} / \mathrm{mL})\end{array}$ & $\begin{array}{c}\text { Standard added } \\
(\mu \mathrm{g} / \mathrm{mL})\end{array}$ & Total amount & Recovery & \% Recovery \\
\hline Piperine & $\mathbf{8 0}$ & 60.4 & 48.3 & 108.7 & 108.5 & 99.8 \\
\hline & $\mathbf{1 0 0}$ & 60.4 & 60.4 & 120.8 & 121.2 & 100.3 \\
\hline & $\mathbf{1 2 0}$ & 60.4 & 72.4 & 132.8 & 131.9 & 99.3 \\
\hline
\end{tabular}

Table 4: Robustness results of piperine and embelin

\begin{tabular}{|c|c|c|c|}
\hline $\begin{array}{c}\text { Parameter } \\
\text { (n=3) }\end{array}$ & Deviation & \multicolumn{2}{|c|}{$\%$ RSD } \\
\hline Flow rate & $0.9 \mathrm{~mL} / \mathrm{min}$ & 1.69 & 1.24 \\
\hline $\begin{array}{c}\text { Column } \\
\text { temperature }\end{array}$ & $1.1 \mathrm{~mL} / \mathrm{min}$ & 1.36 & 0.79 \\
\hline Wavelength & $27^{\circ} \mathrm{C}$ & 1.49 & 0.48 \\
\hline & 287 & 1.49 & 1.03 \\
\hline & 289 & 1.37 & 0.86 \\
\hline
\end{tabular}

\# n: number of injections

\section{Limit of detection (LOD) and limit of quantitation (LOQ)}

LOD and LOQ are expressed as follows:

$\mathrm{LOD}=3 \sigma / \mathrm{S}$

$\mathrm{LOQ}=10 \sigma / \mathrm{S}$

Where, $\sigma$ is the standard deviation of the responses and $S$ is the slope of the calibration curve.

LOD and LOQ of piperine were found to be 1.20 and $3.56 \mu \mathrm{g} / \mathrm{mL}$,

respectively, and that of embelin were found to be 0.31 and $0.92 \mu \mathrm{g} / \mathrm{mL}$, respectively.

A low LOD and LOQ indicate that the method is sensitive.

\section{CONCLUSION}

The present paper describes a novel rapid RP-HPLC method for the simultaneous estimation of phenylephrine and embelin in the herbal formulation. This developed method was validated as per the $\mathrm{ICH}$ guidelines and results found to be linear, accurate, precise, repeatable, sensitive for the detection and quantification of both drugs. Hence, the proposed method was found to be satisfactory and can be applied for routine qualitative and quantitative analysis of piperine and embelin in an herbal formulation containing these markers as one of the ingredients.

Acknowledgment: The authors are thankful to the Oriental College of Pharmacy for providing necessary research facilities.

\section{Authors' Contributions}

All authors have equally contributed toward the preparation of the manuscript.

\section{Conflicts of Interest}

Authors declare that no conflicts of interest exist in this research work.

\section{REFERENCES}

1. Subramani Parasuraman, Gan Thing, Sokkalingam Dhanaraj; Polyherbal formulation: Concept of Ayurveda; Pharmacognosy review. 2014;8(16):73-80. Doi: 10.4103/0973-7847.134229, PMID: 25125878

2. Bhattacharjee Abhishek; An overview on phytosome as a novel drug delivery system for herbal drugs, International journal of innovative pharmaceutical sciences and research, 2015;3(6):730-739. ISSN: 23472154

3. Kumari Rajesh, Kotecha Mita; A review on the standardization of herbal medicines; International journal of pharma sciences and research, 2016;7(2):2529. ISSN: 0975-9492

4. Kumar Sakesh, Deshmukh Rahul; Embelin as a potential drug molecule: a review; Journal Pharmacognosy and natural Products. 2017;3(3):2472-0992. DOI:10.4172/2472-0992.1000144

5. Dogra RKS, Khanna Santosh, Shanker Ravi; Immunotoxicological effects of piperine in mice;Toxicology. 2004;196(3):229-236. doi:10.1016/j.tox.2003.10.006, PMID:15036749

6. Gorgani Leila, Mohammadi Maedeh, Najafpour Ghasem D, Nikzad Maryam; Piperine- the bioactive compound of black pepper: from isolation to medicinal formulation; Comprehensive reviews in food science and food safety. 2017;16:124-140. Doi: 10.1111/15414337.12246.

7. Rastogi Shruti, Bhatia Amandeep K, Kushwaha Ashish, Pandey Manoj K, Sharma Alok, Prakash Jai, Singh GN; Development and validation of a liquid chromatography method for determination of embelin in crude extract of Embelia ribes; Asian Journal of 
Biomedical and Pharmaceutical Sciences. 201;04(36): 9-13. Doi: 10.15272/ajbps.v4i36.554, ISSN: 2249-622X

8. Pathan Imran, Patel Rakesh K, Bhandhari Anil; Standardization, development, validation of spectrophotometric method for simultaneous estimation of embelin and gallic acid as individual and in combination in ayurvedic churna formulation; Asian Journal of Pharmaceutical and Clinical research. 2013;6(9):170-175. ISSN: 0974-2441.

9. Jain Vandana, Shaikh Sultana; Development and validation of a RP-HPLC method for the simultaneous determination of curcumin, piperine and camphor in an Ayurvedic formulation; International Journal of
Pharmacy and Pharmaceutical Science. 2018;10(4): 115-21. Doi: 10.22159/ijpps.218v10i4.25216

10. Shaikh Sultana, Jain Vandana; A novel RP-HPLC method for simultaneous estimation of ellagic, quercetin and piperine in ayurvedic formulations; Asian journal of pharmaceutical and clinical research. 2018;11(6):312317.

DOI: https://doi.org/10.22159/ajpcr.2018.v11i6.25627

11. International Conference on Harmonization of Technical Requirements for Registration of Pharmaceuticals for Human Use. Validation of Analytical Procedures: Text and Methodology ICH Q2 (R1); 2005.

Source of Support: The author(s) received no financial support for the research, authorship, and/or publication of this article.

Conflict of Interest: The author(s) declared no potential conflicts of interest with respect to the research, authorship, and/or publication of this article.

For any question relates to this article, please reach us at: editor@globalresearchonline.net

New manuscripts for publication can be submitted at: submit@globalresearchonline.net and submit_ijpsrr@rediffmail.com 